03

\title{
Исследование ловушек носителей заряда в объемном оксиде галлия $\beta-\mathrm{Ga}_{2} \mathrm{O}_{3}$
}

\author{
() Е.В. Иванова ${ }^{1}$, П.А. Дементьев ${ }^{1}$, М.В. Заморянская ${ }^{1}$, Д.А. Закгейм ${ }^{2}$, Д.Ю. Панов ${ }^{2}$, В.А. Спиридонов ${ }^{2}$, \\ А.В. Кремлева ${ }^{2}$, М.А. Одноблюдов ${ }^{2,3}$, Д.А. Бауман ${ }^{2}$, А.Е. Романов ${ }^{1,2}$, В.Е. Бугров ${ }^{2}$ \\ ${ }^{1}$ Физико-технический институт им. А.Ф. Иофрфе РАН, \\ Санкт-Петербург, Россия \\ ${ }^{2}$ Национальный исследовательский университет ИТМО, \\ Санкт-Петербург, Россия \\ ${ }^{3}$ Санкт-Петербургский политехнический университет Петра Великого, \\ Санкт-Петербург, Россия \\ E-mail: ivanova@mail.ioffe.ru
}

Поступила в Редакцию 11 ноября 2020 г.

В окончательной редакции 11 ноября 2020 г.

Принята к публикации 7 декабря 2020 г.

Исследованы объемные образцы $\beta-\mathrm{Ga}_{2} \mathrm{O}_{3}$, выращенные методом Чохральского. На основании исследований динамики поглощенного тока и катодолюминесценции было показано, что в образце наблюдается локализация заряда обоих знаков. Продемонстрировано, что локализация электронов приводит к существенному уменьшению интенсивности катодолюминесценции.

Ключевые слова: объемный оксид галлия, люминесценция, ловушки носителей заряда.

DOI: 10.21883/FTT.2021.04.50705.236

\section{1. Введение}

Оксид галлия привлекает внимание исследователей в связи с тем, что является перспективным материалом для оптоэлектроники. Это связано с тем, что этот материал является широкозонным полупроводником с интенсивной собственной люминесценцией. Ширина запрещенной зоны оксида галлия составляет $4.8-4.9 \mathrm{eV}$ при комнатной температуре (в зависимости от состава и структурной модификации кристалла). Особый интерес к этому материалу связан с возможностью получения объемного оксида галлия методами Чохральского и Степанова [1]. В связи с этим за последнее время опубликовано достаточно много работ, посвященных исследованию люминесцентных и электрических свойств объемных кристаллов, пленок и наноструктур оксида галлия [2-6]. Исследования проводятся как для чистых, так и для легированных материалов.

Спектры люминесценции оксида галлия, как правило, представляют собой широкие полосы излучения в УФ и видимом диапазоне: зеленая полоса излучения с максимумом интенсивности при $2.39 \mathrm{eV}$ (GB), голубая - при $2.65 \mathrm{eV}(\mathrm{BB})$ и УФ-полоса - при $3.1 \mathrm{eV}$ (UVB). Зеленая полоса излучения наблюдается только в легированных кристаллах, например, при легировании $\mathrm{Be}, \mathrm{Ge}$ и $\mathrm{Sn}$. Голубая и УФ-полосы излучения регистрируются как в чистых, так и в легированных кристаллах. Многочисленные исследования показали, что УФ-люминесценция проявляется во всех оксидах галлия независимо от способа их получения. Природу этой полосы связывают с автолокализованным экситоном $[7,8]$. Голубая полоса излучения наблюдается у легированных образцов, а также у нелегированных, но характеризующихся высокой электропроводностью. Механизм возбуждения голубой полосы до сих пор не имеет однозначной интерпретации. Многие авторы связывают эту полосу с присутствием кислородных вакансий, которые определяют электронный тип проводимости нелегированного оксида галлия $[9,10]$. Важную роль в механизме возникновения голубой полосы излучения играют также вакансии галлия и образование кластеров кислородных вакансий [11]. Большое влияние на люминесцентные свойства и электропроводность оказывают ловушечные состояния в оксиде галлия. Исследование ловушечных состояний для данного материала проводилось методами термолюминесценции и рентгеновской фотоэлектронной спектроскопии (XPS) [12,13]. В этих работах было показано, что тип и содержание ловушек связаны с содержанием легирующих примесей и кислородных вакансий. Также в этих работах было показано, что отжиг оксида галлия в окислительной среде существенно влияет на электрические свойства и интенсивность люминесценции материала. Это подтвердило особую роль кислородных вакансий в этом материале. Однако XPS дает основание делать выводы о составе только поверхностных слоев, а не объемного материала. В результате однозначного понимания природы люминесценции полос видимого диапазона спектра и их связи с электропроводностью оксида галлия и природой ловушечных состояний пока нет. В связи с этим в настоящей работе предлагается новый подход - одновременное измерение динамики люминесценции и поглощенного тока при непрерывном 
возбуждении электронным пучком. Такой подход позволяет наблюдать локализацию носителей заряда и влияние зарядового состояния ловушек на люминесцентные свойства.

Целью настоящей работы было исследование ловушек в оксиде галлия оригинальным методом на основе катодолюминесцентных исследований и измерений динамики поглощенного тока при облучении образцов электронным пучком.

\section{2. Метод роста}

Исследуемые монокристаллы $\beta-\mathrm{Ga}_{2} \mathrm{O}_{3}$ были получены вытягиванием из расплава по методу Чохральского в ростовой установке „Ника-3“ с индукционным нагревом (производство ФГУП ЭЗАН, Черноголовка). В качестве исходного материала использовался порошкообразный $\mathrm{Ga}_{2} \mathrm{O}_{3}$, чистота реактива составляла $99.99 \%$ (4N), тигель был изготовлен из иридия. Вытягивание кристаллов проводилось на затравку из сапфира в атмосфеpe двуокиси углерода $\mathrm{CO}_{2}$ при давлении около 1 Bar. Подробности технологического процесса описывались нами ранее в $[14,15]$. Выращенные кристаллы имели цилиндрическую форму диаметром $\sim 20$ и длиной $\sim 15 \mathrm{~mm}$. Образцы для исследований были получены из кристаллов путем резки и скалывания по плоскостям скольжения.

\section{3. Методики исследования}

Катодолюминесцентные (КЛ) исследования и измерения динамики поглощенного тока проводились на электронно-зондовом микроанализаторе САМЕВАХ (Cameca), оснащенном оптическим спектрометром для исследования спектров катодолюминесценции [16], с возможностью получения катодолюминесцентных изображений и измерения динамики поглощенного тока [17]. Катодолюминесцентные изображения были получены при диаметре электронного пучка $100 \mu \mathrm{m}$, энергии электронного пучка $15 \mathrm{keV}$ и токе $30 \mathrm{nA}$. Спектры катодолюминесценции регистрировались при следующих параметрах электронного пучка: энергия электронов $15 \mathrm{keV}$, ток электронного пучка $10 \mathrm{nA}$ и диаметр $10 \mu \mathrm{m}$. При исследовании процессов захвата носителей тока и изменения люминесценции ток электронного пучка варьировался в диапазоне 1-30 nA, диаметр варьировался в диапазоне $10-30 \mu \mathrm{m}$.

Нестабильность интенсивности КЛ под действием стационарного электронного пучка в растровых электронных микроскопах давно известна. В большинстве случаев наблюдается уменьшение интенсивности КЛ со временем. Это может быть связано с образованием дефектов под действием электронов, локальным нагревом образца, формированием контаминационной пленки и присутствием в образце ловушечных состояний. В связи с этим при анализе экспериментальных данных необходимо учитывать все возможные факторы. При работе с высокотемпературными материалами, такими как оксид галлия, образование дефектов под действием электронов с энергиями до $25 \mathrm{keV}$ невозможно, локальный нагрев образцов при выбранных условиях эксперимента не превышает несколько градусов, а как было показано ранее, образование контаминационной пленки приводит к медленному спаду интенсивности катодолюминесценции [18]. Это было учтено при обработке экспериментальных данных.

При облучении твердого тела (мишени) электронным пучком часть электронов отражается от образца, остальные электроны тормозятся, а излишний заряд стекает с образца, образуя поглощенный ток, который регистрируется наноамперметром. Если в образце присутствуют точечные дефекты - ловушки электронов или дырок, то часть носителей заряда может быть захвачена этими ловушками. Этот процесс влияет на динамику поглощенного тока. Характерное время захвата носителей зависит от плотности мощности возбуждения и может составить от долей секунд до нескольких часов. При торможении электронов в твердом теле большая часть их потерянной энергии расходуется на образование электроннодырочных пар, которые в свою очередь могут рекомбинировать с испусканием оптического излучения (катодолюминесценция). Изменение зарядового состояния ловушек может влиять как на отдельные КЛ-полосы [17], так и на интенсивность КЛ-спектра в целом. Соответственно, процесс захвата носителей заряда может проявляться в динамике интенсивности КЛ-полос при непрерывном облучении электронным пучком, причем характерные времена динамики поглощенного тока и динамики КЛ в этом случае должны совпадать.

В работе [17] была предложена модель описания динамики поглощенного тока. В общем виде зависимость поглощенного тока от времени облучения электронным пучком для образца, содержащего по одному типу ловушек электронов и дырок, может быть описана следующим образом:

$$
J=J_{0}-A_{e} \exp \left(-t / \tau_{e}\right)+A_{h} \exp \left(-t / \tau_{h}\right),
$$

где экспонента $A_{e} \exp \left(-t / \tau_{e}\right)$ описывает вклад электронных ловушек, а экспонента $A_{h} \exp \left(-t / \tau_{h}\right)$ - вклад дырочных ловушек. Коэффициенты $A_{e}$ и $A_{h}$ пропорциональны содержанию ловушек в образце, а $1 / \tau_{e}$ и $1 / \tau_{h}$ вероятности захвата электронов и дырок ловушками, соответственно. Следует заметить, что ловушек для носителей обоих знаков может быть несколько типов и, соответственно, экспериментальные зависимости могут быть существенно сложнее. Эта методика использовалась при исследовании ловушек в тонких пленках оксида гафния и тонких пленках диоксида кремния [17].

Такой подход позволяет оценить концентрацию соответствующих ловушек следующим образом. Полный локализованный отрицательный заряд равен $A_{e} \tau_{e}$, соответственно, необходимо определить объем, в котором 


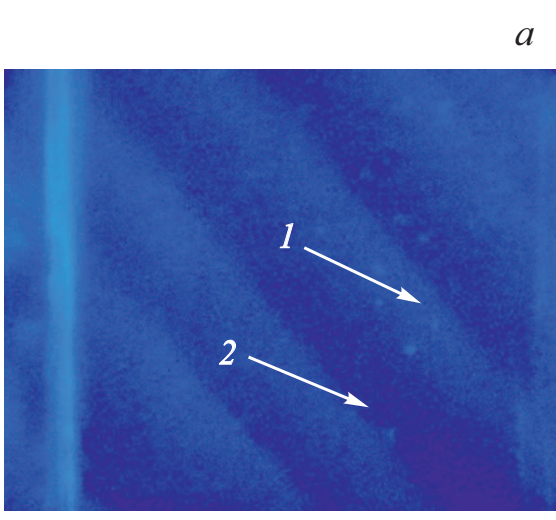

$50 \mu \mathrm{m}$
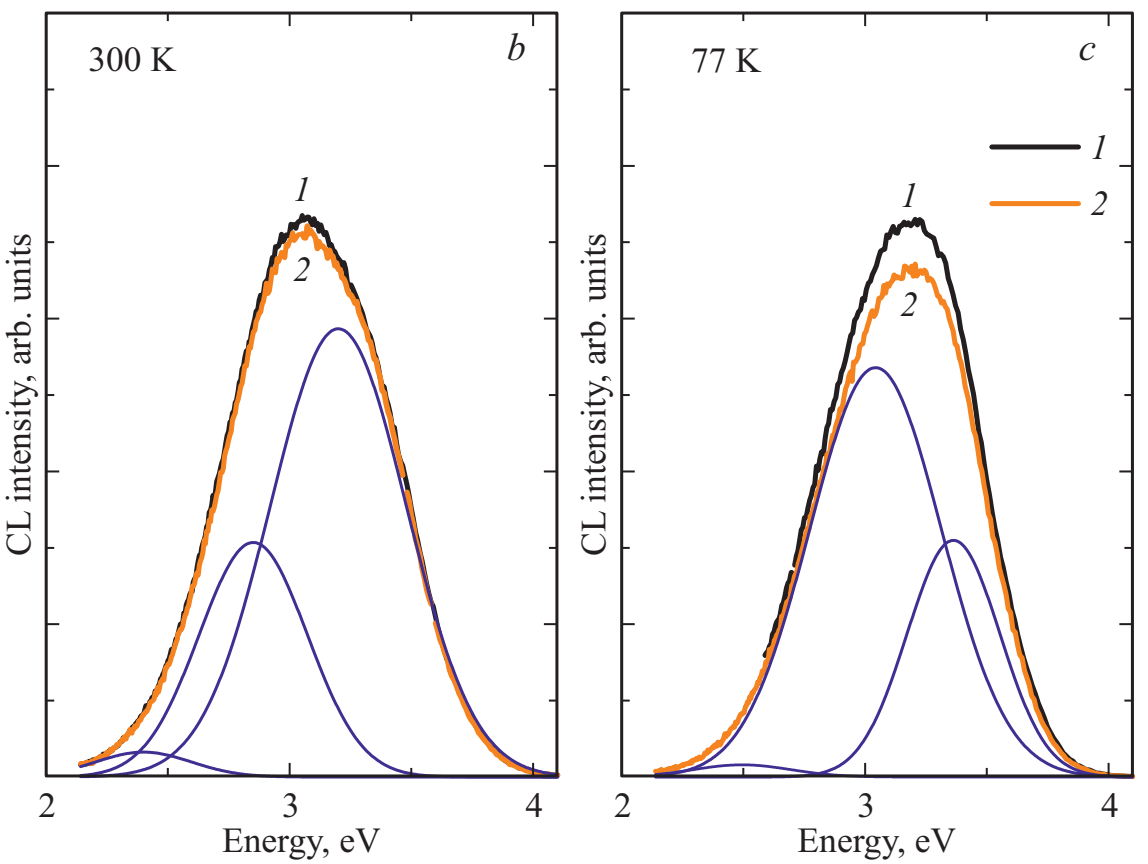

Рис. 1. КЛ-изображение поверхности (100) образца $\beta-\mathrm{Ga}_{2} \mathrm{O}_{3}$ при температуре $300 \mathrm{~K}(a)$ и спектры КЛ при температуре $300 \mathrm{~K}$ (b) и $77 \mathrm{~K}(c)$ (кривые 1 и 2 - спектры образца, полученные в областях с различной яркостью, тонкие линии - аппроксимация спектра КЛ суммой гауссовых кривых).

происходит локализация электронов. В настоящей работе мы считаем, что локализация заряда происходит только в области, в которой тормозятся электроны, соответственно, предполагается, что процесс диссипации заряда существенно медленней, чем локализация заряда. Глубина области торможения электронов рассчитывалась в программе CASINO, плотность $\beta-\mathrm{Ga}_{2} \mathrm{O}_{3}$ принималась равной $6.44 \mathrm{~g} / \mathrm{cm}^{3}$. Для энергии электронного пучка $15 \mathrm{keV}$ рассчитанная глубина области торможения электронов составляла $550 \mathrm{~nm}$.

Рельеф исследуемой поверхности образцов изучался при помощи атомно-силового микроскопа (АСM) Ntegra-Aura (NT-MDT, Зеленоград, Москва).

\section{4. Результаты и обсуждение}

\section{1. Катодолюминесценция образцов оксида галлия}

Были получены КЛ-изображения образца $\beta-\mathrm{Ga}_{2} \mathrm{O}_{3}$ с плоскости (100) (рис. 1, a). На КЛ-изображении видны контрастные полосы, скорее всего, связанные с плоскостью кристаллизации. Вертикальная светлая полоса на КЛ-изображении - трещина по направлению (010). Исследования на АСМ показали, что на поверхности образца присутствуют ступени различной высоты, совпадающие по направлению с контрастными полосами на КЛ-изображении. На рис. 2 приведен пример такой ступени, в данном случае высота ее составляет около $2 \mathrm{~nm}$. Исходя из этого, логично связать контраст

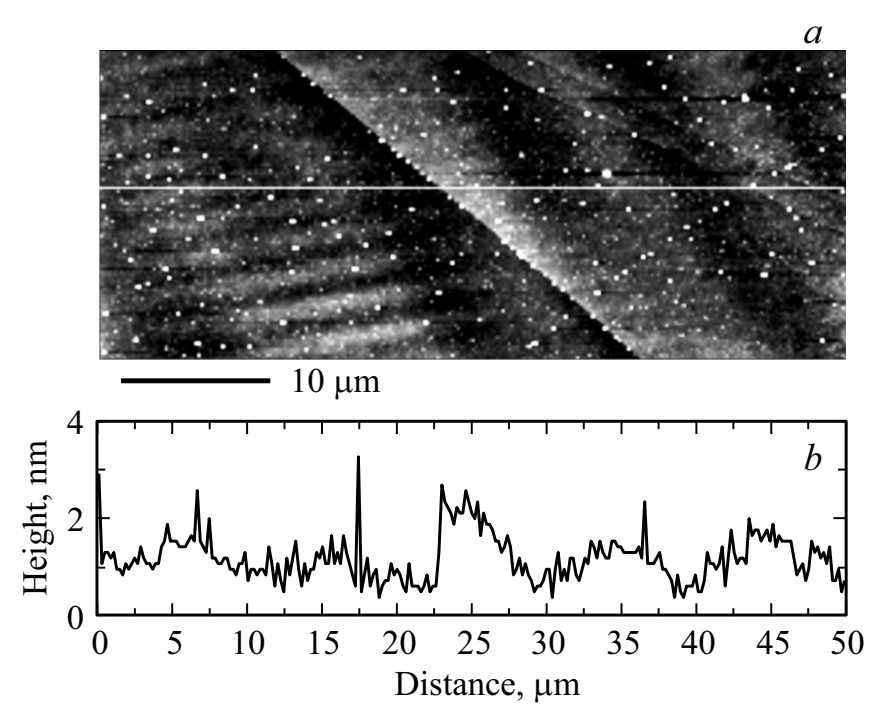

Рис. 2. (a)АСМ-изображение поверхности (100) образца $\beta-\mathrm{Ga}_{2} \mathrm{O}_{3} ;(b)$ профиль рельефа вдоль белой линии на части $(a)$.

КЛ-изображения с такими ступенями. Были получены спектры КЛ из темных и светлых областей на рис. 1, $a$. Из графиков видно, что форма спектров, полученных из областей разной яркости, меняется незначительно. По-видимому, наблюдается неоднородное распределение точечных дефектов в данном кристаллографическом направлении.

Как видно на рис. 1, в спектрах КЛ при температуре $300 \mathrm{~K}$ наблюдаются полосы $3.2 \mathrm{eV}$ (UVB), $2.85 \mathrm{eV}$ (BB) 


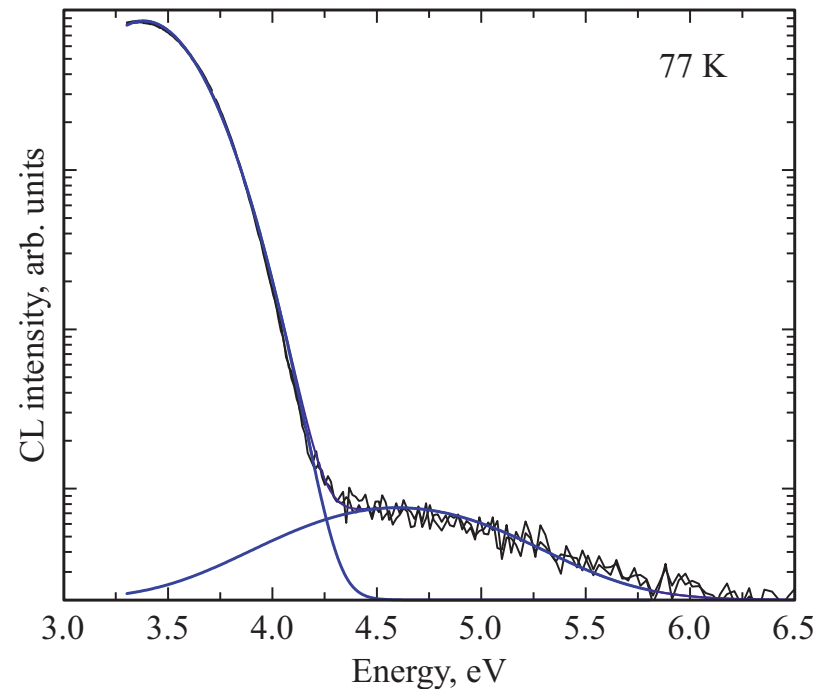

Pис. 3. Спектры КЛ поверхности (100) образца $\beta-\mathrm{Ga}_{2} \mathrm{O}_{3}$ при температуре $77 \mathrm{~K}$ в УФ-диапазоне (полулогарифмический масштаб).

и $2.4 \mathrm{eV}(\mathrm{GB})$, связанные с люминесценцией точечных дефектов, описанных в статье [9]. Видно, что при охлаждении образца происходит рост интенсивности полосы $2.85 \mathrm{eV}$ и уменьшение интенсивности полосы $3.2 \mathrm{eV}$, что также согласуется со статьей [9]. Были получены спектры в УФ-диапазоне при температуре $77 \mathrm{~K}$ (рис. 3), в спектрах наблюдается слабое плечо с максимумом $4.6 \mathrm{eV}$, что связано с краевой люминесценцией.

\section{2. Динамика интенсивности катодолюминесценции и поглощенного тока}

Исследование динамики катодолюминесценции в данных образцах осложнено, поскольку полосы КЛ значительно накладываются друг на друга. Для понимания, какие именно происходят изменения в спектрах с течением времени, были получены спектры КЛ после длительного облучения электронным пучком (рис. 4). Видно, что форма спектров КЛ, полученных при температурах 77 и $300 \mathrm{~K}$, не меняется. Поэтому в дальнейших экспериментах будет исследоваться динамика интенсивности излучения с энергией $3.2 \mathrm{eV}$.

Была исследована динамика поглощенного тока и интенсивности КЛ-полосы $3.2 \mathrm{eV}$ при плотностях тока электронного пучка 0.2 и $0.6 \mathrm{nA} / \mu \mathrm{m}^{2}$ (рис. 5). По временным зависимостям поглощенного тока видно, что при таких условиях наблюдается локализация электронов. Полученные зависимости были аппроксимированы экспонентой, значение $\tau_{e}$ для динамики поглощенного тока при токе электронного пучка $0.2 \mathrm{nA} / \mu \mathrm{m}^{2}-6.15 \mathrm{~s}$, при токе $0.6 \mathrm{nA} / \mu \mathrm{m}^{2}-2.1 \mathrm{~s}$. Соответственно, вероятность захвата электрона пропорциональна плотности тока и, следовательно, количеству электронно-дырочных пар в области их генерации.

Видно, что динамика интенсивности КЛ может быть аппроксимирована суммой двух затухающих экспонент. Длинная составляющая, скорее всего, связана с нарастанием контаминационной пленки. Короткая составляющая совпадает по времени с динамикой поглощенного
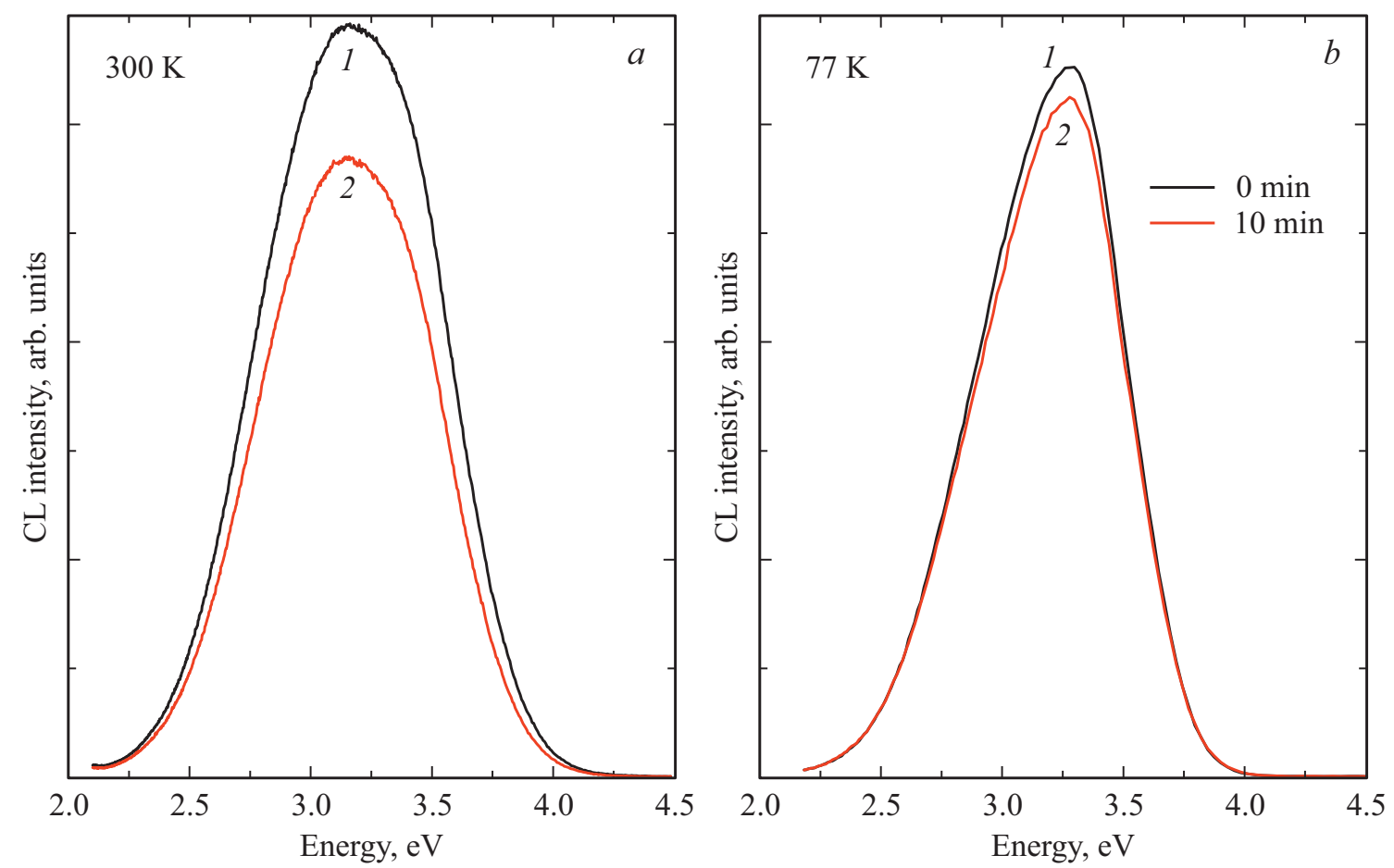

Рис. 4. Спектры КЛ до (кривые 1) и после (кривые 2) облучения электронным пучком в течение 10 min при температурах $300 \mathrm{~K}(a)$ и $77 \mathrm{~K}(b)$. Плотность тока $0.01 \mathrm{nA} / \mu \mathrm{m}^{2}$. 

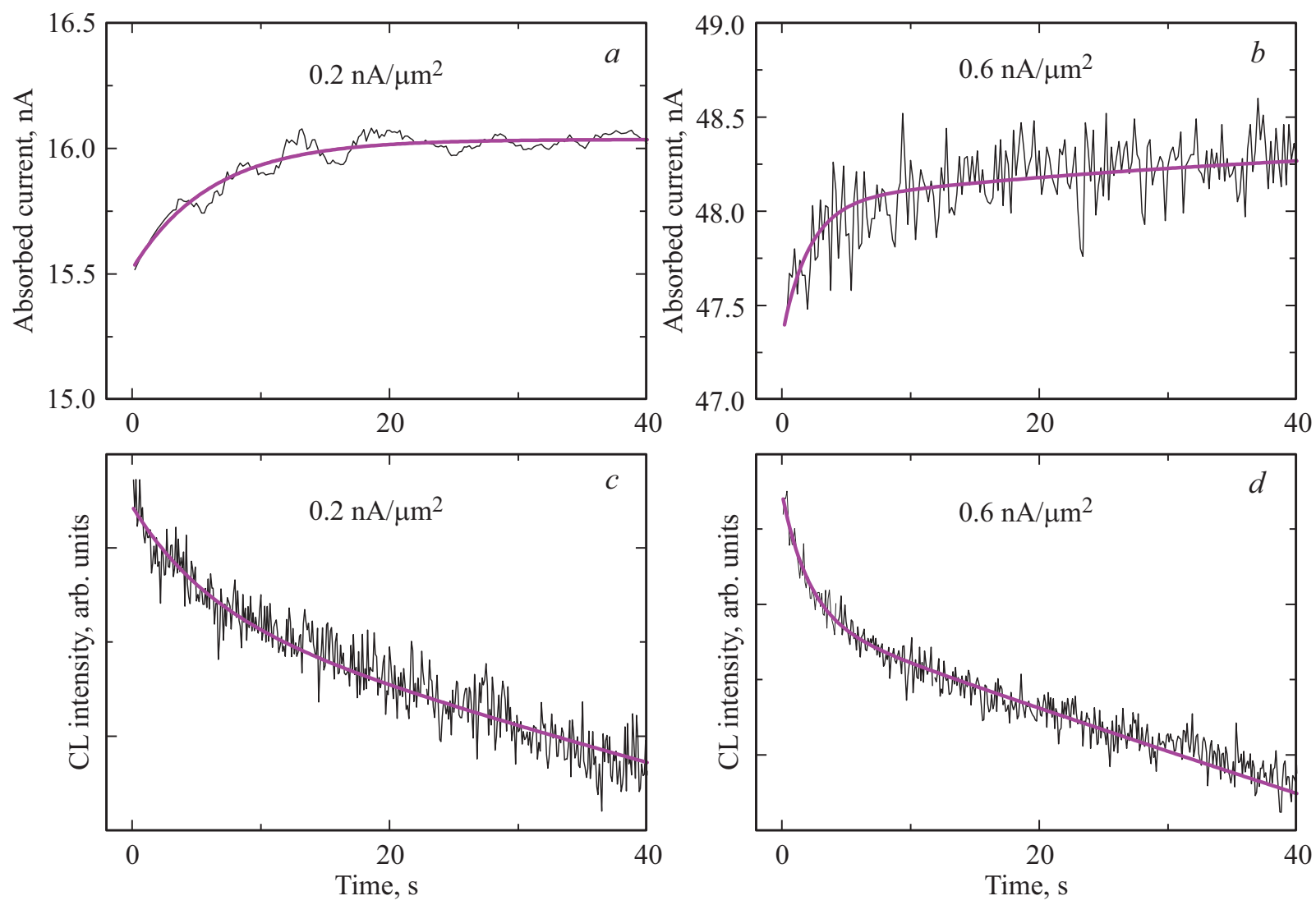

Рис. 5. Динамика поглощенного тока $(a$ и $b)$ и интенсивности КЛ-полосы $3.2 \mathrm{eV}(c$ и $d)$ при различных значениях плотности тока: $0.2 \mathrm{nA} / \mu \mathrm{m}^{2}$ ( $a$ и $\left.c\right)$ и $0.6 \mathrm{nA} / \mu \mathrm{m}^{2}$ ( $b$ и $\left.d\right)$ при температуре $300 \mathrm{~K}$.
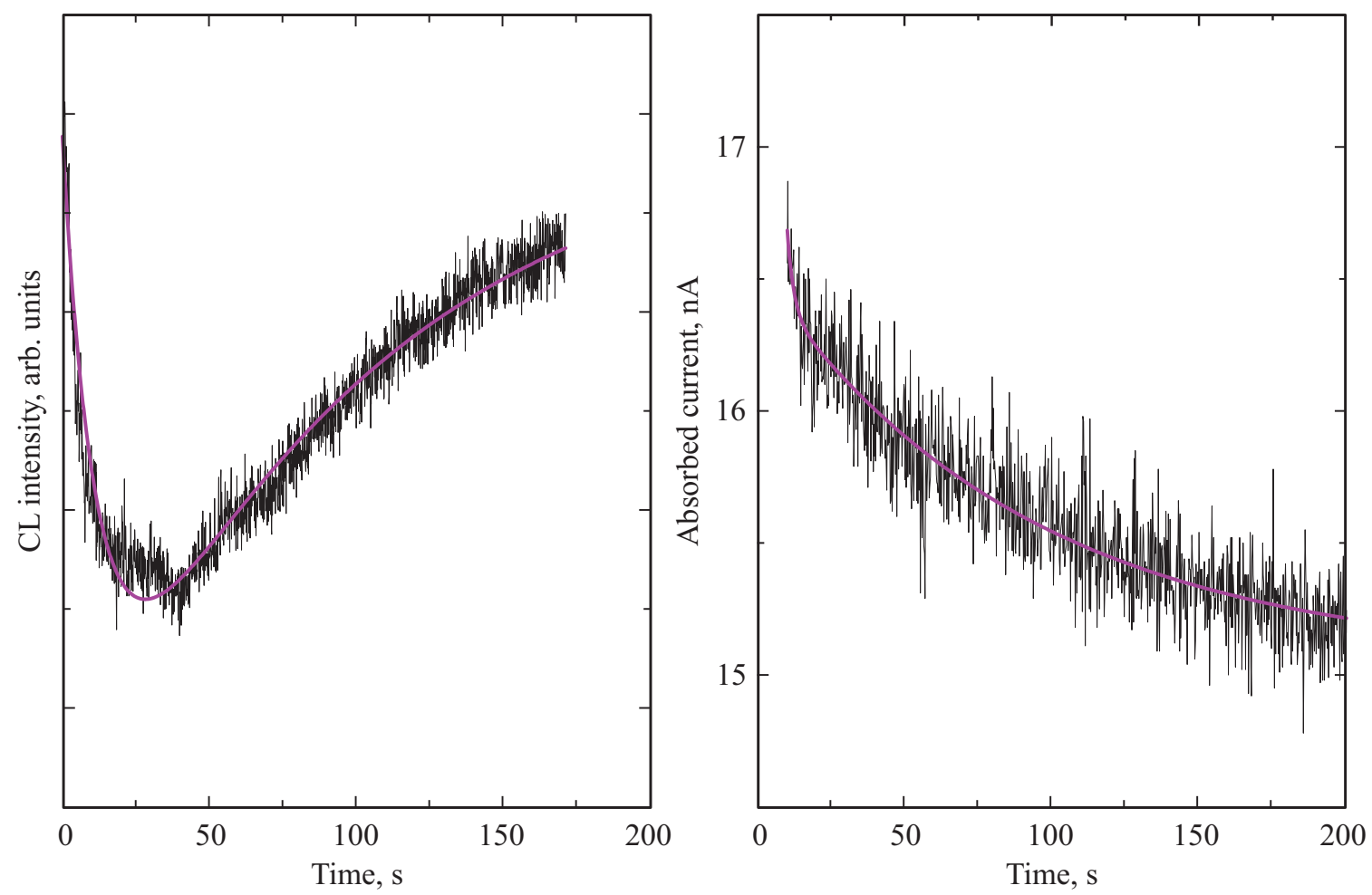

Pис. 6. Динамика интенсивности КЛ и поглощенного тока при температуре $77 \mathrm{~K}$ (плотность тока $0.5 \mathrm{nA} / \mu \mathrm{m}^{3}$ ). 
тока и также меняется при изменении поглощенного тока. Это позволяет утверждать, что короткая составляющая временной зависимости катодолюминесценции связана с локализацией электронов. Так как при локализации электронов происходит уменьшение интенсивности всех наблюдаемых полос, то можно предположить, что дефект, захватывая электрон, становится дополнительным центром безызлучательной рекомбинации, за счет чего происходит уменьшение интенсивности КЛ.

Были получены временные зависимости поглощенного тока и интенсивности КЛ при $77 \mathrm{~K}$ (рис. 6). Видно, что при такой температуре наблюдается локализация положительного заряда. Скорее всего, соответствующие ловушки имеют достаточно маленькую энергию активации и не наблюдаются при комнатной температуре. В динамике интенсивности КЛ при $77 \mathrm{~K}$ наблюдается и затухание, и разгорание люминесценции, разгорание по времени согласуется с динамикой поглощенного тока. Соответственно, при температуре $77 \mathrm{~K}$ наблюдается локализация дырок, которая приводит к увеличению интенсивности катодолюминесценции.

По динамике поглощенного тока было рассчитано содержание ловушек в исследуемом образце. Содержание электронных ловушек составило $(7 \pm 3) \cdot 10^{19} \mathrm{~cm}^{-3}$, содержание дырочных ловушек $-(3 \pm 1) \cdot 10^{21} \mathrm{~cm}^{-3}$.

\section{5. Выводы}

На основании полученных результатов было показано, что в кристаллах $\beta-\mathrm{Ga}_{2} \mathrm{O}_{3}$, выращенных методом Чохральского, наблюдаются ловушки электронов и дырок. По динамике поглощенного тока было оценено содержание ловушек: электронных ловушек - $(7 \pm 3) \cdot 10^{19} \mathrm{~cm}^{-3}$, дырочных ловушек $(3 \pm 1) \cdot 10^{21} \mathrm{~cm}^{-3}$. Было показано, что зарядовое состояние ловушек влияет на интенсивность КЛ-спектра. Видно, что именно локализация электронов приводит к уменьшению интенсивности катодолюминесценции.

\section{Финансирование работы}

Работа выполнена при поддержке Российского научного фонда, проект № 19-19-00686.

\section{Конфликт интересов}

Авторы заявляют об отсутствии конфликта интересов.

\section{Список литературы}

[1] H.F. Mohamed, Ch. Xia, Q. Sai, H. Cui, M. Pan, H. Qi. J. Semicond. 40, 011801 (2019).

[2] R. Jangir, S. Porwal, P. Tiwari, P. Mondal, S.K. Rai, A.K. Srivastava, I. Bhaumik, T. Ganguli. AIP Adv. 6, 035120 (2016).

[3] I. Lopez, M. Alonso-Orts, E. Nogales, B. Mendez. Phys. Status Solidi A 215, 1800217 (2018).
[4] S.J. Pearton, J. Yang, P.H. Cary IV, F. Ren, J. Kim, M.J. Tadjer, M.A. Mastro. Appl. Phys. Rev. 5, 011301 (2018).

[5] S.I. Stepanov, V.I. Nikolaev, V.E. Bougrov, A.E. Romanov. Rev. Adv. Mater. Sci. 44, 63 (2016).

[6] T. Onuma, S. Fujioka, T. Yamaguchi, M. Higashiwaki, K. Sasaki, T. Masui, T. Honda. Appl. Phys. Lett. 103, 041910 (2013).

[7] T. Harwig, F. Kellendonk, S. Slappendel. J. Phys. Chem. Solids 39, 6, 675 (1978).

[8] А.И. Кузнецов, В.Н. Абрамов, Т.В. Уйбо. Оптика и спектроскопия 58, 3, 603 (1985).

[9] L. Binet, D. Gourier. J. Phys. Chem. Solids. 59, 8, 1241 (1998).

[10] V.I. Vasil'tsiv, Ya.M. Zakharko, Ya.I. Prim. Ukr. Fiz. Zh. 33, 1320 (1988)

[11] O.M. Bordun, B.O. Bordun, I.Yo. Kukharskyy, I.I. Medvid. J. Appl. Spectroscopy 84, 1, 46 (2017).

[12] M.M. Islam, D. Rana, A. Hernandez, M. Haseman, F.A. Selim. J. Appl. Phys. 125, 055701 (2019).

[13] H. Cui, Q. Sai, H. Qi, J. Zhao, J. Si, M. Pan. J. Mater. Sci. 54, 12643 (2019).

[14] P.N. Butenko, D.I. Panov, A.V. Kremleva, D.A. Zakgeim, A.V. Nashchekin, I.G. Smirnova, D.A. Bauman, A.E. Romanov, V.E. Bougrov. Mater. Phys. Mech. 42, 802 (2019).

[15] Д.А. Закгейм, Д.Ю. Панов, В.А. Спиридонов, А.В. Кремлева, А.М. Смирнов, Д.А. Бауман, А.Е. Романов, М.А. Одноблюдов, В.Е. Бугров. Письма в ЖТФ 46, 22, 43 (2020).

[16] М.В. Заморянская, С.Г. Конников, А.Н. Заморянский. ПТЭ, 4, 62 (2004).

[17] П.А. Дементьев, Е.В. Иванова, М.В. Заморянская. ФТТ 61 , 8,1448 (2019).

[18] К.Н. Орехова, Ю.М. Серов, П.А. Дементьев, Е.В. Иванова, В.А. Кравец, В.П. Усачева, М.В. Заморянская. ЖТФ 89, 9 , 1412 (2019).

Редактор Е.Ю. Флегонтова 